\title{
The Study of Resistance and Relative Mechanism of the Low Efficiency Single Silicon Solar Cell
}

\author{
Yue Wang ${ }^{1, a}$, Xue $\mathrm{Li}^{1, \mathrm{~b}}$ and Chunjie Wang ${ }^{2, \mathrm{c}^{*}}$ \\ ${ }^{1}$ College of New Energy, Bohai University, Jinzhou, 121013, China \\ ${ }^{2}$ College of Engineering, Bohai University, Jinzhou, 121013, China \\ a'wangsuiyue@foxmail.com, ${ }^{b} 347515383 @ q q . c o m,{ }^{c}$ cjwang@foxmail.com
}

Keywords: Single silicon; Solar cell; Resistance

\begin{abstract}
One of the important factors affecting the photoelectric conversion efficiency ( $\eta$ ) of solar cells (SCs) is the resistance which are consist of shunt resistance (Rsh) and series resistance (Rs). In order to improve the performance of silicon cell, it is essential to characterize the $\mathrm{Rs}_{\mathrm{s}}$ and $\mathrm{Rsh}$ of multijunction solar cells. In this paper the resistance and related parameters of silicon solar cell were measured by Corescan instrument. Further analysis of resistance play an important role in both the production and and the development of solar cell.
\end{abstract}

\section{Introduction}

In recent years, with the rapid development of related industries, the wire length and current of solar cell chips are gradually increasing, which leads to the power loss of series resistors increasing. Therefore, to investigate the change of series resistance and understand the relative mechanism is very essential and important not only for the quality control of batteries and industrial production, but also for the development of solar cells[1]. In addition, a considerable part of the loss of power of solar cells comes from the leakage current of inside of battery. Due to the significantly influence on the performance of solar cells, the number of parallel resistance should be increased as much as possible[2].

The series resistance (Rs) of a solar cell is mainly composed of the contact resistance between the metal and the semiconductor, the resistance of the semiconductor layer, and the resistance of the front side to the external conductive electrode[3]. The main source of the parallel resistance (Rsh) mainly comes from the semiconductor material, including the pn-junction of the solar cell, the edge defects of the solar cell surface, the concentration of impurity, and the defects caused by the carrier compound or capture and so on. Therefore, to analyze and understand the relative mechanism of the series resistance and parallel resistance of solar cell has a significantly role on optimizing the manufacturing technique of solar cells and improving the utilization rate of industrial batteries.

\section{The Principle of Resistance Generation of Solar Cells}

The effect of series resistance of solar cells on electrical performance can be analyzed as follows[4,5]. Assuming that the parallel resistance (Rsh) is large enough which can be neglected and only series resistance (Rs) is considered. The output current (I) of the solar cell can be expressed as[6]:

$$
I=I_{\mathrm{ph}}-I_{0}\left\{\exp \left[\frac{\mathrm{q}\left(V+I R_{\mathrm{s}}\right)}{\mathrm{n} K T}\right]-1\right\}
$$


where $I_{p h}$ is the current generated by the sunlight; $I_{0}$ is the reverse saturation dark current; $\mathrm{V}$ and $\mathrm{I}$ are the voltage and current acting on the load; $\mathrm{n}$ is the quality factor of the pn-junction; $\mathrm{K}$ is the Boltzmann constant; $\mathrm{T}$ is Thermodynamic temperature.

The case when $\mathrm{V}=0$, short circuit current $\mathrm{I}_{\mathrm{sc}}$ is:

$$
I_{\mathrm{sc}}=I_{\mathrm{ph}}-I_{D}=I_{\mathrm{ph}}-I_{0}\left(\exp \frac{\mathrm{q} R_{\mathrm{s}} I}{K T}-1\right)
$$

where $I_{D}$ denotes the forward injection current of the pn-junction solar cell.

The case when $\mathrm{I}=0$, open circuit voltage (Voc) is:

$$
V_{\mathrm{oc}}=\frac{K T}{\mathrm{q}} \cdot \ln \left(\frac{I_{\mathrm{ph}}}{I_{0}}+1\right)
$$

It can be seen from equation (3), when the parallel resistance is not considered, the magnitude of the series resistance has no influence on the open circuit voltage. However, it can be noted from equation (2) that the series resistance affects the value of short-circuit current and the filling factor. The bigger the series resistance is, the smaller value of circuit current and the filling factor will $b \mathrm{e}^{[7-9]}$. On the other hand, the effect of the parallel resistance on the electrical properties can be investigated as follows ${ }^{[10]}$ : assume the series resistance Rs is small enough can be ignored, only consider the parallel resistance. The output current of the solar cell (I) can be expressed as:

$$
I=I_{\mathrm{ph}}-I_{0}\left[\exp \left(\frac{\mathrm{q} V}{K T}\right)-1\right]-\frac{V}{R_{\mathrm{sh}}}
$$

The case when $\mathrm{V}=0$, short circuit current $\left(\mathrm{I}_{\mathrm{sc}}\right)$ is:

$$
I_{\mathrm{sc}}=I_{\mathrm{ph}}
$$

The case when $\mathrm{I}=0$, open circuit voltage $(\mathrm{Voc})$ is:

$$
V_{\mathrm{oc}}=\frac{\mathrm{k} T}{\mathrm{q}} \ln \left(\frac{I_{\mathrm{ph}}}{I_{0}}-\frac{V_{\mathrm{oc}}}{I_{0} R_{\mathrm{sh}}}+1\right)
$$

In equation (5), the short-circuit current is independent of the shunt resistor. Moreover, the magnitude of the shunt resistor has no effect on the short-circuit current when the series resistance is not taken into account. However, it can be seen from equation (6) that the parallel resistance affects the values of the open circuit voltage and the fill factor. The values of open circuit voltage and fill factor decreased as the decreasing of parallel resistance. ${ }^{[11]}$

\section{Experiment}

In the study, the resistance measurement of monocrystalline silicon battery was carried out by using Holland Corescan battery performance analyzer with a scanning head which including a light source and a metal probe. During the scanning process, the battery chip is short-circuited and the scanning head is scanned at a fixed pitch in the $\mathrm{X}$-axis direction. The metal probe is scratched on the surface of the battery sheet. The photogenerated current is generated on the cell sheet by the light source and the voltage at the illumination position Value, through the calculation to characterize the front of the battery chip and the value of parallel resistance. In this paper, in order 
to measure the excellent process and to find the shortcomings in the production process, the performance of single-crystal silicon cells which produced by different production lines have been investigated. The basic parameters of single crystal silicon cells A and B selected in the experiment are shown in Table 1.

Table 1 The basic parameters of the solar cell sample

\begin{tabular}{|c|c|c|c|c|c|c|}
\hline sample & $\begin{array}{c}\text { Open circuit } \\
\text { voltage } \\
\mathrm{V}(\mathrm{mv})\end{array}$ & $\begin{array}{c}\text { Short circuit } \\
\text { current } \\
\mathrm{I}(\mathrm{mA})\end{array}$ & $\begin{array}{c}\text { Fill } \\
\text { factor } \\
\mathrm{FF}\end{array}$ & $\begin{array}{c}\text { Conversion } \\
\text { efficiency } \\
\eta\end{array}$ & $\begin{array}{c}\text { Series } \\
\text { resistance } \\
\mathrm{Rs}(\Omega)\end{array}$ & $\begin{array}{c}\text { Parallel } \\
\text { resistanceR } \\
\operatorname{sh}(\Omega)\end{array}$ \\
\hline Cell A & 596.39 & 584.90 & 0.22 & $9.10 \%$ & 0.50 & 1.16 \\
\hline Cell B & 626.09 & 999.96 & 0.33 & $12.76 \%$ & 0.43 & 1.33 \\
\hline
\end{tabular}

\section{Results and Discussion}

Detection and Analysis of Series Resistance. Fig.1 is the image of the series resistance of the battery A. It can be seen from the fig.1, the white region in Fig. 1 (a) with high voltage, and the battery A has a high series resistance. For fig. 1(a), the white areas are separated by different gate lines, and represented by regions 1, 2 and 3, respectively. Area 1 located in the cell center position, where the series resistance will be increased due to the high sintering temperature; Area 2 at both sides of the main grid line with non-uniform series resistance, which can be attributed to the uneven doping; The area appearing in the region 3 is scattered, but they are all located on the fine grid line, where the grid lines are broken.
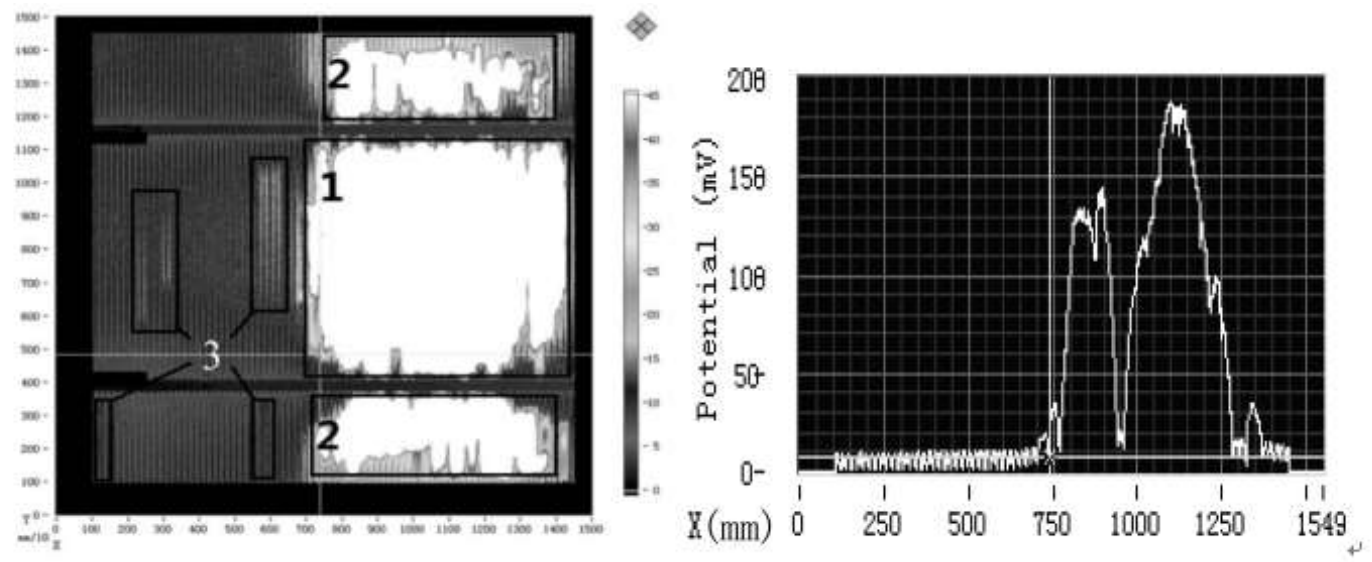

Figure 1. The image of monocrystalline silicon A series resistance

(a) Corescan detection of battery A series resistance diagram

(b)The relationship between the voltage of the battery A and the measurement position

Fig. 1 (b) is the coordinate diagram of the voltage of the battery A varying with the scanning position. The abscissa represents the spot where the probe was swept on the battery plate, and the coordinates of the lower left corner of the battery plate are $(0,0)$. The probe is scanned perpendicular to the fine grid line along the $\mathrm{x}$-axis. The ordinate represents the corresponding voltage value of the probe scan. The normal voltage range of the battery is in the range of $0 \sim 15 \mathrm{mv}$. It can be found from the Fig. 1 (b), the voltage increases in the range of $750 \sim 1250 \mathrm{~mm}$, and the values are much larger than $15 \mathrm{mv}$, which corresponds to the position of white areas 1 and 2 . In addition, the resistance value of region 3 is much smaller than those of regions 1 and 2 . 

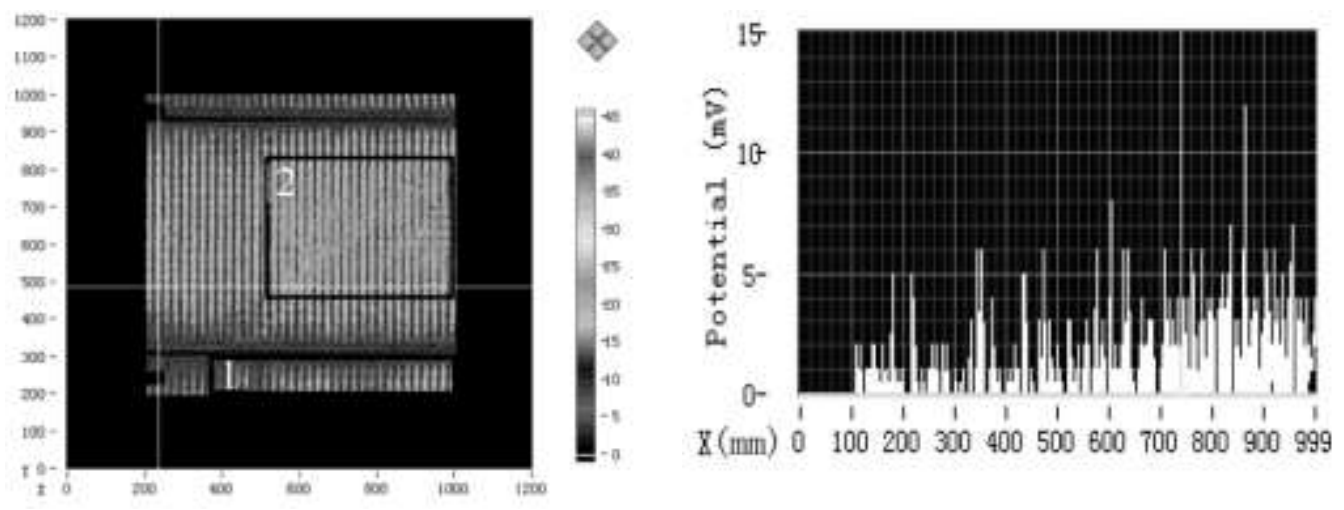

Figure 2. The image of monocrystalline silicon series resistance

(a)Corescan detection of battery B series resistance diagram

(b)The relationship between the voltage of the battery B and the measurement position

Fig. 2 is the image of the series resistance of silicon solar cell B. For figure 2 (a), the uneven spot in 1 regional located at the edge of cell can be attributed to the uneven distribution of resistance caused by the problem of the isolation edge. Area 2 located at the center of the battery plate with uneven brightness changes. Generally, the excessive sintering temperature will leads to the increaseing of the series resistance. Fig. 2(b) is the coordinate diagram of the voltage change of monocrystalline silicon solar cell B with scanning position. Lots of voltage amplitude fluctuations can be observed. Such fluctuating data points corresponding to the light and shade area of the battery $\mathrm{B}$, and the voltage values are less than $15 \mathrm{mv}$, indicating the larger series resistance of monocrystalline silicon solar cells also belongs to the normal range value.

By contrast the results of series resistance of two batteries, the efficiency of the battery decreased to less than $10 \%$ after the voltage exceeds $15 \mathrm{mV}$. Therefore, it can be concluded that the increase of series resistance will lead to the reduction of short-circuit current, and reduce the efficiency of solar cells further.

Detection and Analysis of Shunt Resistance. Fig. 3 is the image of parallel resistance detection of monocrystalline silicon solar cell A. It can be seen from Fig. 3 (a), the cell is divided into regions 1 and 2 according to the unevenness of the color black and white. The region 1 is located at the center of the battery plate, the decreased parallel resistance is due to the defects of the silicon material or the contamination of the silver aluminum paste on the positive surface; Region 2 exhibits a discontinuous distribution of light and shade throughout the whole battery, the decresed shunt resistance can be attributed to the doping of SiC.Fig. 3 (b) is the coordinate diagram of the voltage change of monocrystalline silicon solar cell A with scanning position. When detecting the parallel resistance of solar cells, the voltage under normal conditions is less than $10 \mathrm{mv}$. In Fig. 3 (b), the point at $870 \mathrm{~mm}$ corresponds to a large area of light at area 1 where the parallel resistance is smaller. Other places appear too much voltage point, but they are less than $10 \mathrm{mv}$, and belong to the normal range. 

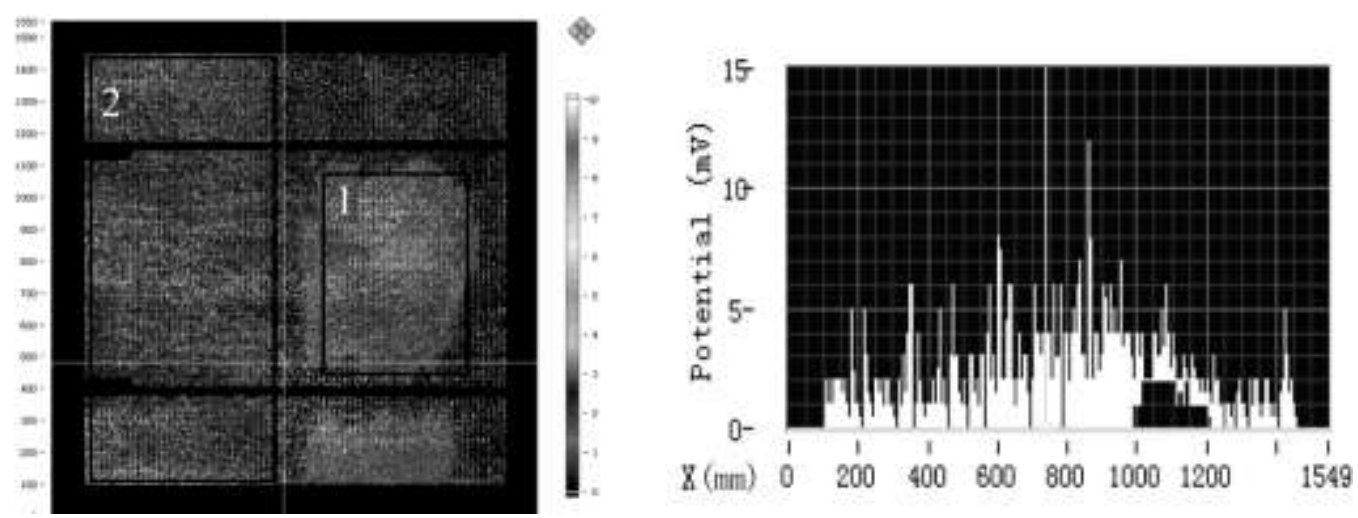

Figure 3. The image of parallel resistance of monocrystalline silicon A (a)Corescan detection of battery A parallel resistance diagram

(b)The relationship between the voltage of the battery $A$ and the measurement position
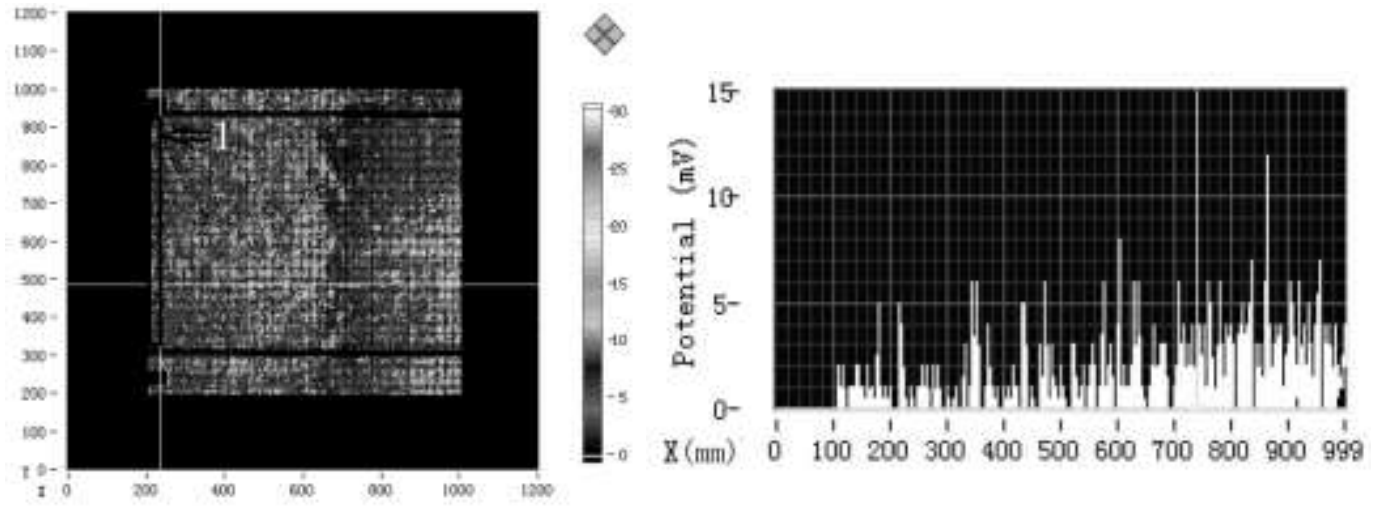

Figure 4. The image monocrystalline silicon a parallel resistance

(a)Corescan detection of battery B parallel resistance diagram

(b)The relationship between the voltage of the battery B and the measurement position

Fig. 4 is the image of parallel resistance for battery B. It can be seen from Fig. 4 (a), lots of bright spots located at the region 1 and the edge of the cell chip, which are attributed to the edge separation problem, and resulting in a decrease in the parallel resistance. In the case of the whole solar panel, the point of uneven light and dark can be observed, the doping of SiC leads to the decrease of the shunt resistance.

The plot of the voltage of the battery B with the scanning position are shown in Fig. 4 (b). The point of great increase in voltage occurs at $870 \mathrm{~mm}$, where the parallel resistance is too small. Other places appear too much voltage point, but most are less than $10 \mathrm{mv}$ and belong to the normal range.

By contrast the results of the detection of two parallel resistors, it can be found that the dark area of the image of the battery A was much lower than that of the battery B, and the corresponding parallel resistance was small. Therefore, it can be concluded that the decreased parallel resistance leads to a reduction in both of the open circuit voltage and the fill factor, and further leads to a reduction in the efficiency of the solar cell.

By testing the resistance of two low-efficiency batteries, the results show that the main reason for the low efficiency of the two batteries is the low doping quality of the wafer which the decline the battery performance during production process of high sintering temperature. 


\section{Conclusion}

Series resistance and shunt resistance play a significantly role on the performance of solar cells. The selection of raw materials and improper control of industrial process conditions have a great influence on the resistance of batteries, which further effect the efficiency of solar cells. The Corescan instrument has good detection effect on the series and parallel resistance of solar cells. The mechanism of the series parallel resistance is too large or too small were discussed in detail. Combined with the voltage of the coordinate map to determine the location of the defect point. The changes of resistance were also investigated based on the change of voltage, and further evaluate the mechanism of uneven distribution of series and parallel resistors.

\section{Acknowledgments}

This work was supported by the National Natural Science Foundation of China under Grant no. 11404032.11404034; and the Foundation of Education Department of Liaoning Province no. LY2016002. Natural Science Foundation of Liaoning Province no. 20170540014, 20170540009.

\section{Reference}

[1] J.G.Shao, X.L.Huang and Y.Chen, Analysis of series resistance of crystalline silicon solar cells and its measurement method [J].Solar energy1(2009):25-29.

[2] T.J.Chen,J.J.Tu and D.X.Wang, A Measuring Method for Parallel Resistance of Solar Cells [J].Semiconductor optoelectronics, 19(1998):227-228.

[3] D Pysch, A. Mette and S.W. Glunz, A review and comparison of different methods to determine the series resistance of solar cells [J].Solar Energy Materials \& Solar Cells, 91(2007):1698-1706.

[4] J.B. Zheng, J. Ren,W. Guo .Simulation of the influence of internal resistance of solar cell on its output characteristics [J].Journal of Solar Energy,27(2006):121-125.

[5] Y. S.Kim , S. M.Kang and B. Johnston. A novel method to extract the series resistances of individual cells in a photovoltaic module [J].Solar Energy Materials \& Solar cells, ,115(2013):21-28.

[6] L.Peng, Y.Sun and Z.Meng. A new method for determining the characteristics of solar cells [J].Journal of Power Sources,227(2013):131-136.

[7] J.Y.Wei .Approximate exponential relationship between solar cell efficiency and series resistance [J].Journal of Solar Energy,25(20043):356-358.

[8] J.Wang, H.Wang and H. Yang, An accurate algorithm for series resistance of solar cell[J].Power technology,32(2008):681-683.

[9] M.A.Mintairov, V. Vevstropov and A.Kalyuzhnyi.Photoelectric determination of the series resistance of multijunction solar cells [J] Semiconductors,,46(2012):1051-1058.

[10] V. Dalessandro, P. Guerriero and S. Dalitntol. A straightforward method to extract the shunt resistance of photovoltaic cells from current-voltage characteristics of mounted arrays [J].Solid-State Electronics,63(2011):130-136.

[11]J.Y.Wei, The exponential relationship between the filling factor of the solar cell and the parallel resistance[J].Journal of Yunan Normal University,33(2013):38-40. 